\title{
ANALISIS PENGGUNAAN ADVERBIA PADA MAHASISWA PROGRAM STUDI SASTRA JEPANG UNIVERSITAS UDAYANA
}

\author{
Putu Ayu Muliani ${ }^{1}$, I Nyoman Sedeng ${ }^{2}$, I Made Madia ${ }^{3}$ \\ ${ }^{1,2,3}$ Fakultas IImu Budaya, Universitas Udayana \\ e-mail: putuayumulianii@gmail.com
}

\begin{abstract}
Abstrak
Adverbia atau fukushi dalam istilah bahasa Jepang merupakan kelas kata yang dapat menerangkan verba, adjektiva, maupun adverbia lainnya. Secara umum beberapa fukushi muncul dengan akhiran kalimat atau klausa jenis tertentu. Penelitian ini bertujuan untuk mengetahui kesalahan dalam penggunaan fukushi. Data penelitian ini diperoleh dari hasil tes mahasiswa. Metode yang digunakan dalam penelitian ini adalah deskriptif kuantitatif dan kualitatif. Berdasarkan analisis kalimat dan hasil jawaban dari responden, responden cenderung menerjemahkan secara harafiah fukushi tersebut. Responden kurang mengetahui makna dan penggunaan fukushi tersebut dengan tepat, sehingga terjadi kesalahan di dalam memilih kalimat yang tepat sesuai dengan fukushi tersebut. Pemahaman mengenai fukushi secara tepat menjadi faktor yang penting dalam pembelajaran bahasa Jepang. Dari analisis yang dilakukan, diharapkan dapat dijadikan bahan evaluasi serta untuk mencari solusi dalam mencari metode pembelajaran yang tepat untuk meningkatkan kemampuan penggunaan fukushi.
\end{abstract}

Kata kunci : kesalahan penggunaan, adverbia, fukushi, penggunaan fukushi

\begin{abstract}
Fukushi or adverb is a class of word that modify verbs, adjectives, and other adverbs. Some fukushi commonly occur with certain kinds of sentence or clause endings. This study aims to determine misused of Japanese adverbs (fukushi). The study data was obtained from student's test results. The method used in this study is descriptive quantitative and qualitative. Based on sentence analysis and the answers from respondents, respondents tend to translate literally the adverbs. Respondents did not know the meaning and usage of the adverbs properly, so there was an error in choosing the right sentence according to adverbs. From the analysis carried out, its able to expected to be used as material for evaluation and to find solutions in finding the right learning methods to improve the ability to use Japanese adverbs.
\end{abstract}

Keywords : Misused, Japanese adverb, fukushi, usage of fukushi

\section{PENDAHULUAN}

Bahasa merupakan salah satu alat komunikasi terpenting dalam kehidupan sehari-hari karena dengannya seseorang dapat menyampaikan suatu ide, pikiran, dan keinginan. Kata sebagai unsur penyusun utama dalam sebuah bahasa memiliki peranan penting. Karena penyusunan kata, dapat berpengaruh terhadap makna yang ingin disampaikan kepada lawan bicara. Sehingga penyusunan kata yang baik, dapat menyampaikan maknanya secara baik pula, dan begitupun sebaliknya Oleh karena itu untuk berkomunikasi dengan baik, kita perlu memilah kata yang baik pula (Noviastuti, 2017).
Setiap tiga tahun sekali, Japan Foundation (2013) melakukan survei tentang jumlah pembelajar bahasa Jepang di berbagai negara di luar Jepang. Berdasarkan pada hasil survei yang dilakukan pada tahun 2012, diketahui bahwa secara keseluruhan, jumlah pembelajar bahasa Jepang di dunia meningkat 9,1\% dibandingkan hasil survei tahun 2009. Di Indonesia, total pembelajar bahasa Jepang mencapai 872.406 orang dan menduduki urutan ke-2 (Wahidati, 2018).

Bahasa Jepang merupakan salah satu bahasa asing yang unik dan memiliki banyak perbedaan dengan bahasa Indonesia. Salah satu perbedaan tersebut dapat dilihat dari unsur kosakatanya. Kosakata memiliki peranan yang penting ketika mempelajari 
bahasa Jepang. Pernyataan ini diperkuat oleh pendapat Yamauchi (2004 : 6) (Yuliani, 2018).

Kosakata merupakan komponen inti dari kemampuan berbahasa. Hal tersebut merupakan modal awal bagi peserta didik untuk mampu mempelajari keterampilan berbahasa seperti menyimak, berbicara, membaca, dan menulis. Keterampilan berbahasa memerlukan penguasaan kosakata yang memadai. Hal tersebut diperlukan agar gagasan yang ingin disampaikan dapat tersalurkan dengan baik. Penguasaan kosakata yang memadai dapat menentukan kualitas berbahasa seseorang. Pembelajaran kosakata harus dilakukan secara efektif dan dilakukan pembelajaran yang sesuai dengan tujuan komunikasi bermakna dalam kehidupan sehari-hari serta dilaksanakan secara aktif, kreatif, dan menyenangkan.

$$
\text { Kosakata dalam KBBI berarti }
$$

perbendaharaan kata.7 Kosakata adalah himpunan kata yang dimiliki oleh seseorang atau entitas lain, atau merupakan bagian dari suatu bahasa tertentu. Kosakata seseorang didefinisikan sebagai himpunan semua katakata yang dimengerti oleh orang tersebut atau semua kata-kata yang kemungkinan akan digunakan oleh orang tersebut untuk menyusun kalimat baru.8 (Susanti, 2016).

Adverbia adalah kata yang dipakai untuk memerikan verba, ajektiva, proposisi, atau adverbia lain , misalnya sangat, lebih, tidak, dan sebagainya (Kridalaksana, 2011: 3) (Nusarini, 2017).

Kosakata memiliki peran penting dalam pembelajaran bahasa. Meskipun kosakata tidak selalu dijadikan prioritas dalam pembelajaran bahasa, perhatian pada kosakata dalam pembelajaran bahasa telah meningkat dan para pendidik sadar akan perlunya pendekatan yang sistematik untuk pembelajaran kosakata. Salah satu faktor meningkatnya status kosakata dalam pembelajaran bahasa adalah berkembangnya pendekatan komunikatif dan metode yang menekankan pemahaman.

Kata dalam bahasa Jepang dikelompokkan ke dalam hinshi (kelas kata). Menurut Koizumi (1995) kelas kata bahasa Jepang terdiri dari meishi (nomina), doushi (verba), joshi (partikel), fukushi (adverbia), jodoshi (kata bantu verba), setsuzokushi (konjungsi) dan kantoushi (kata seru). Fukushi atau dalam istilah bahasa Indonesia yang disebut dengan adverbia adalah suatu jenis kata yang sifatnya memberikan keterangan terhadap verba dan adjektiva. Tsujimura (2004: 132) mengemukakan bahwa di dalam kalimat, fukushi memodifikasi keiyoushi 'adjektiva', doushi 'verba', kata keterangan yang lain, bahkan dapat memodifikasi keseluruhan kalimat. Fukushi merupakan kelas kata yang tidak mengalami perubahan bentuk dan tidak dapat menjadi subjek, predikat, dan pelengkap di dalam kalimat (Sudjianto dan Dahidi, 2018: 165). Fukushi dibagi menjadi tiga jenis, yaitu; joutai no fukushi, teido no fukushi dan chinjutsu no fukushi.

Takanao (dalam Sudjianto dan Dahidi, 2018: 166-168) menyatakan bahwa jootai no fukushi merupakan fukushi yang berfungsi untuk menerangkan verba yang ada pada bagian berikutnya. Joutai no fukushi juga dapat berfungsi sebagai keterangan cara untuk melakukan kegiatan tertentu. Contoh dari fukushi tersebut yaitu; sikkari 'dengan kuat', yukkuri 'perlahan', hakkiri 'dengan jelas', shibaraku 'sebentar', dan lain sebagainya. Fukushi tersebut umumnya digunakan untuk menerangkan verba. Contoh pada klausa hakkiri mieru 'terlihat dengan jelas'. Fukushi hakkiri menerangkan verba mieru 'terlihat', sehingga arti dari klausa tersebut menjadi 'terlihat dengan jelas'. Kemudian, teido no fukushi merupakan fukushi yang berfungsi untuk menerangkan tingkat, taraf, kualitas atau derajat keadaan yoogen (verba, adjektiva-i, adjektiva-na). Contoh dari fukushi tersebut antara lain taihen 'sangat', kanari 'agak', hotondo 'hampir', dan lain sebagainya. Contoh dari penggunaan fukushi tersebut yaitu kanari takai. Fukushi kanari 'agak' menerangkan adjektiva takai 'tinggi', sehingga klausa tersebut berarti menjadi 'agak mahal'. Sedangkan chinjutsu no fukushi adalah fukushi yang memerlukan cara pengucapan khusus. Contoh dari fukushi tersebut yaitu; marude 'seolah-olah', tatoe 'walaupun', douzo 'silahkan', dan lain sebagainya. Pada umumnya, fukushi ini diikuti dengan ekspresi atau akhir kalimat tertentu.

Dalam kalimat, fukushi muncul disertai dengan ekspresi yang umumnya mengikuti fukushi tersebut. Contohnya fukushi semete 'setidaknya'. Fukushi tersebut bermakna bahwa pembicara memberikan perkiraan terendah dari standar idealnya. Dalam kalimat, semete umumnya disertai dengan bentuk keinginan. Hal-hal tersebut sering kali diabaikan oleh peserta didik dan cenderung hanya menerjemahkan fukushi tersebut secara harafiah, sehingga penggunaan fukushi menjadi kurang sesuai di dalam konteks kalimat.

Dalam praktik pengajarannya, fukushi sering kali tidak mendapat perhatian khusus. Fukushi hanya sekadar diajarkan di dalam pelajaran sehingga kemampuan penggunaan 
fukushi peserta didik masih rendah. Hal ini perlu mendapat perhatian mengingat kemampuan penggunaan bahasa sangat berpengaruh dari penguasaan kosakata peserta didik tersebut. Fukushi ini juga harus dipelajari dan dipahami sesuai dengan konteks penggunaannya. Dalam bahasa Jepang, beberapa fukushi muncul dengan akhiran kalimat atau klausa tertentu.

Berdasarkan permasalahan tersebut, pemahaman mengenai fukushi secara tepat menjadi faktor yang penting dalam pembelajaran bahasa Jepang. Ini dilakukan agar peserta didik dapat menggunakan fukushi dengan baik dan benar. Jika peserta didik mampu memahami fukushi dengan benar, maka kemampuan pembelajar dalam menggunakan fukushi pun akan semakin meningkat. Pada penelitian ini, peneliti menganalisis kesalahan penggunaan fukushi, sehingga apabila diketahui kesalahan yang terjadi pada mahasiswa, hasilnya dapat dijadikan sebagai bahan evaluasi serta untuk mencari solusi dalam meningkatkan pemahaman dan kemampuan mahasiswa dalam menggunakan fukushi.

\section{METODE}

Penelitian ini menggunakan rancangan penelitian deskriptif kualitatif kuantitatif. Lokasi penelitian ini adalah di Program Studi S-1 Sastra Jepang Universitas Udayana yang berlokasi di Jalan P.Nias, Denpasar. Subjek dalam penelitian ini dikhususkan pada mahasiswa semester VI yang sedang menempuh studi di Program Studi S-1 Sastra Jepang. Jumlah subjek yang digunakan dalam penelitian ini sebanyak 29 mahasiswa. Objek penelitian ini adalah kemampuan penggunaan fukushi yang dikhususkan pada tiga fukushi yaitu zuibun, sukkari dan semete.

Dalam penelitian ini pengumpulan data dilakukan berdasarkan hasil tes untuk mengetahui kemampuan penggunaan fukushi dari subjek penelitian. Tes tersebut dilakukan pada bulan Mei 2019. Soal tes diperoleh dari buku kumpulan latihan soal untuk Japanese Language Proficiency Test (JLPT) untuk tingkat N4 sampai N3. Tes yang diberikan berupa soal pilihan ganda yang memuat empat kalimat dengan menggunakan fukushi tersebut. Pada soal tersebut, mahasiswa diminta untuk memilih kalimat yang sesuai dengan penggunaan fukushi yang terdapat di soal. Teknik analisis data disesuaikan dengan jenis data yang dikumpulkan. Metode yang digunakan dalam penelitian ini adalah deskriptif kuantitatif dan kualitatif. Deskriptif kuantitatif yaitu penyajian data berupa tabel dan persentase yang disajikan secara deskriptif yang mengukur tingkat pemahaman mahasiswa terhadap penggunaan fukushi. Metode deskriptif kualitatif kuantitatif disajikan melalui deskriptif interpretatif yang mengukur tingkat pemahaman kemampuan penggunaan fukushi mahasiswa. Teknik penyajian data dalam penelitian ini adalah teks yang bersifat naratif disertai dengan penyajian data berupa tabel.

\section{HASIL DAN PEMBAHASAN}

Data dalam penelitian ini diperoleh dari hasil penyebaran instrumen kepada mahasiswa semester VI Program Studi S-1 Sastra Jepang Universitas Udayana. Sampel yang digunakan dalam penelitian ini sebanyak 29 mahasiswa. Instrumen penelitian yang digunakan adalah tes. Penyebaran instrumen tes dilaksanakan pada hari Kamis tanggal 1 Mei 2019 dengan alokasi waktu selama 30 menit. Tes yang diberikan kepada mahasiswa berupa soal pilihan ganda. Dalam soal tersebut, mahasiswa diminta untuk memilih kalimat yang tepat sesuai dengan penggunaan fukushi.

Setelah pelaksaan tes, data nilai responden dihitung frekuensi jawaban yang telah diberikan. Dalam penelitian ini difokuskan pada butir soal yang memuat fukushi zuibun, sukkari, dan semete. Berikut adalah frekuensi hasil jawaban yang diberikan oleh responden.

Tabel 1. Tabel Frekuensi Hasil Jawaban Responden

\begin{tabular}{lllll}
\hline Opsi jawaban & $(1)$ & $(2)$ & $(3)$ & $(4)$ \\
\hline Zuibun & 2 & 2 & 3 & 22 \\
$\begin{array}{l}\text { Sukkari } \\
\text { Semete }\end{array}$ & 12 & 3 & 12 & 2 \\
\hline $\begin{array}{l}\text { Setelah didapat frekuensi hasil jawaban } \\
\text { adalah }\end{array}$ & 4 & $\begin{array}{l}\text { menghitung } \\
\text { jawaban tersebut. Hasil penghitungan }\end{array}$ & $\begin{array}{c}\text { persentase } \\
\text { responden, langkah }\end{array}$
\end{tabular}


persentase tersebut diinterpretasikan berdasarkan tabel interpretasi kategori tingkatan nilai maksimum dan minimum. Adapun tabel yang dimaksud adalah sebagai berikut.

Tabel 2. Tabel Interpretasi Nilai Maksimum Minimum

\begin{tabular}{|c|c|}
\hline Persentase & Interpretasi \\
\hline $85 \%-100 \%$ & Sangat tinggi \\
\hline $75 \%-84 \%$ & Tinggi \\
\hline $60 \%-74 \%$ & Cukup tinggi \\
\hline $45 \%-59 \%$ & Sedang \\
\hline $30 \%-44 \%$ & Cukup rendah \\
\hline $15 \%-29 \%$ & Rendah \\
\hline $0 \%-14 \%$ & Sangat rendah \\
\hline
\end{tabular}

Tabel 3. Frekuensi dan Interpretasi Kesalahan Penggunaan Fukushi

\begin{tabular}{llll}
\hline \multirow{2}{*}{ Fukushi } & \multicolumn{2}{l}{ Jawaban salah } & Interpretasi \\
\cline { 2 - 3 } & Frekuensi & Persentase & \\
\hline Zuibun & 7 & $24 \%$ & Rendah \\
Sukkari & 15 & $52 \%$ & Sedang \\
Semete & 18 & $62 \%$ & Cukup tinggi
\end{tabular}

Berdasarkan tabel tersebut, diketahui bahwa butir soal yang memuat fukushi zuibun frekuensi kesalahan sebanyak 7 dengan persentase $24 \%$. Ini dapat diinterpretasikan bahwa kesalahan penggunaan fukushi zuibun 'cukup' adalah rendah. Pada butir soal yang memuat fukushi sukkari 'benar-benar', frekuensi kesalahan sebanyak 15 dengan persentase 52\%. Hal tersebut dapat diinterpretasikan bahwa kesalahan penggunaan fukushi tersebut adalah sedang. Kemudian, butir soal yang memuat fukushi semete 'setidaknya', frekuensi kesalahan sebanyak 18 dengan persentase 62\%. Ini dapat diinterpretasikan bahwa kesalahan penggunaan fukushi semete adalah cukup tinggi. Adapun pembahasan kesalahan penggunaan fukushi zuibun, sukkari, dan semete adalah sebagai berikut.

\section{Zuibun 'cukup'}

Zuibun mempunyai makna lebih dari satu dan makna tersebut dapat berubah sesuai dengan konteks kalimat. Zuibun dapat bermakna menunjukkan makna jumlah yang dianggap banyak atau cukup dan digunakan dalam hubungan yang akrab dan ragam lisan.
Selain itu, zuibun juga menunjukkan makna 'waktu yang lama atau panjang' (Mulya, 2013:

31). Adapun analisis kesalahan penggunaan fukushi zuibun adalah sebagai berikut.

Soal yang memuat fukushi zuibun adalah sebagai berikut.

1. Konna ni junbi sureba, mou zuibun deshou.Ini-

DAT/bersiap/kalau/juga/cukup/KOP

Kalau persiapan seperti ini, sudah cukup'

2. Zuibun $6 \mathrm{ji}$ ni okimasu ga, kyou wa $8 \mathrm{ji}$ made nete imashita.

cukup/jam 6-DAT/bangun/tapi/hari iniTOP/jam 8/sampai/tidur 'saya (ingin) bangun tidur di jam 6 tetapi masih tidur jam 8 hari ini'

3. Ashita wa zuibun ame deshou besok-TOP/cukup/hujan/KOP 'Besok katanya cukup (turun) hujan'

4. Kinou wa zuibun osoku made shigoto wo shimashita.kemarin-

TOP/cukup/lambat/sampai/pekerjaan-

AKU/melakukankemarin saya bekerja sampai cukup larut'

Berikut adalah tabel hasil penghitungan frekuensi jawaban yang diberikan oleh responden. 
Tabel 4 Tabel Frekuensi Jawaban Zuibun

\begin{tabular}{llllll}
\hline \multirow{2}{*}{ Zuibun } & Opsi jawaban & $(1)$ & $(2)$ & $(3)$ & $(4)$ \\
\cline { 2 - 6 } & Jawaban & 2 & 2 & 3 & 22 \\
Jawaban benar: (4) Persentase kesalahan: $24 \%$ & & $7 \%$ & $7 \%$ & $10 \%$ & $76 \%$ \\
\hline
\end{tabular}

Berdasarkan tabel tersebut, pilihan jawaban yang paling banyak dipilih oleh responden adalah pilihan jawaban nomor (4) sebanyak 22 orang. Pilihan jawaban nomor (3) dipilih sebanyak 3 orang, pilihan jawaban nomor (2) dan (1) masing-masing sebanyak 2 orang. Persentase kesalahan jawaban yang diberikan oleh responden pada soal tersebut adalah $24 \%$.

Dalam bahasa Jepang, zuibun 'cukup' digunakan untuk menerangkan tingkat, taraf atau derajat dari yoogen (verba dan adjektiva). Zuibun mempunyai fungsi untuk menunjukkan tingkat yang sangat, misalnya, luar biasa, banyak, lama, dan sebagainya dan seringkali disertai dengan perasaan heran atau di luar dugaan si pembicara.

Pada soal ini, responden paling banyak menjawab salah terdapat pada pilihan jawaban (3) sebanyak tiga responden. Jawaban (3) tidak tepat karena pada kalimat tersebut, zuibun menerangkan nomina ame 'hujan'. Dalam pilihan jawaban nomor (1), penggunaan fukushi zuibun tidak tepat karena zuibun yang terdapat pada kalimat tersebut tidak menerangkan verba atau adjektiva. Kata tersebut digunakan untuk menjelaskan persiapan yang cukup, sehingga penggunaannya tidak tepat. Pilihan jawaban nomor (2) juga tidak tepat karena zuibun pada kalimat tersebut menerangkan nomina 6ji 'jam 6'. Seperti yang dijelaskan sebelumnya, zuibun biasanya digunakan untuk menerangkan verba dan adjektiva. Di soal ini responden yang menjawab dengan benar sebanyak 22 responden. Pilihan jawaban nomor (4) merupakan jawaban yang benar karena zuibun pada kalimat tersebut menerangkan adjektiva osoku 'lambat', sehingga maknanya menjadi 'cukup lambat' atau 'cukup larut'. Dalam kalimat tersebut, zuibun memberi makna bahwa pekerjaan yang dilakukan sampai cukup larut tersebut di luar dugaan si pembicara.

Tabel 5. Tabel Frekuensi Jawaban Sukkari

\section{Sukkari 'benar-benar'}

Sukkari merupakan fukushi yang bermakna menunjukkan sebuah kondisi yang telah mencapai derajat 100 persen (Mulya, 2013: 47). Berdasarkan pengertian tersebut, sukkari digunakan ketika hal yang diterangkan telah atau sudah terjadi dan benar-benar mencapai sepenuhnya. Adapun kesalahan penggunaan fukushi sukkari adalah sebagai berikut.

Adapun butir soal yang memuat fukushi sukkari adalah sebagai berikut.

1. Chuugakusei ni nattara, sukkari benkyoushinakya dame dayo.

Murid SMP-DAT/jadi-btk.peng/benarbenar/harus belajar/tidak boleh/KOP

kalau jadi murid SMP, harus benar-benar belajar'

2. Megane o kakenai to, soko ni aru mono mo sukkari shite yoku mienai

Kacamata-AKU/pakai-

btk.neg/kalau/disitu-LOK/ada/benda-

PAR/benar-benar/baik/lihat-btk.neg

'kalau tidak memakai kacamata, benda yang ada disitu benar-benar tidak terlihat dengan baik'

3. Tomodachi to hanashite iru uchi ni, soto wa sukkari kuraku natte ita

Teman/dan/bicara/selagi/luar-

TOP/benar-benar/gelap/jadi

'selagi berbicara dengan teman, di luar benar-benar menjadi gelap'

4. Tabemono mo nomimono mo sukkari arimasu kara, dondon meshiagatte kudasai

Makanan-PAR/minuman-PAR/benar-

benar/ada/karena/banyak/makan/silakan Karena benar-benar ada makanan dan minuman, silakan makan banyak'

Berikut adalah tabel hasil penghitungan frekuensi jawaban yang diberikan oleh responden.

\begin{tabular}{l|l|llll}
\hline \multirow{3}{*}{ Sukkari } & Opsi jawaban & $(1)$ & $(2)$ & $(3)$ & $(4)$ \\
& Jawaban & 12 & 3 & 12 & 2 \\
& Persentase & $41 \%$ & $11 \%$ & $41 \%$ & $7 \%$ \\
\hline
\end{tabular}

Jawaban benar: (3) Persentase kesalahan: 52\% 
Berdasarkan tabel tersebut, pilihan jawaban yang paling banyak dipilih oleh responden adalah pilihan jawaban nomor (1) dan (3) masing-masing sebanyak 12 orang. Pilihan jawaban nomor (2) dipilih sebanyak 3 orang dan pilihan jawaban nomor (4) dipilih sebanyak 2 orang. Persentase kesalahan jawaban yang diberikan oleh responden pada soal tersebut adalah 52\%.

Berdasarkan penjelasan penggunaan sukkari yang telah disebutkan sebelumnya, sukkari digunakan untuk menerangkan kondisi yang benar-benar sepenuhnya telah terjadi. Sukkari dapat menerangkan verba dan adjektiva.

Pada soal ini, responden paling banyak menjawab salah terdapat pada pilihan jawaban (1) sebanyak 12 responden. Dilihat dari pilihan jawaban tersebut, kalimat (1) penggunaan sukkari tidak tepat karena menyatakan kondisi yang belum terjadi. Sukkari menerangkan verba benkyou suru 'belajar' yang berkonjugasi menjadi benkyoushinakya 'harus belajar'. Hal tersebut merupakan hal yang belum terjadi karena kalimat sebelumnya menyatakan pengandaian. Pada kalimat (2), penggunaan sukkari tidak tepat karena menerangkan hal yang belum terjadi. Sukkari melekat pada verba shite yang berkonjugasi dari bentuk dasar suru yang berarti 'melakukan'. Pada kalimat (4), penggunaan sukkari tidak tepat karena tidak menunjukkan kondisi yang benar-benar telah terjadi. Penggunaan fukushi sukkari yang tepat adalah pilihan jawaban nomor (3). Pada kalimat (3) merupakan penggunaan sukkari yang tepat karena dalam kalimat tersebut, sukkari menerangkan adjektiva kuraku yang berkonjugasi dari adjektiva kurai 'gelap'. Dalam kalimat tersebut, kondisi telah benarbenar menjadi gelap.

\section{Semete 'setidaknya'}

Semete merupakan fukushi yang digunakan untuk mengekspresikan kepuasan minimal dari pembicara. Fukushi ini biasanya digunakan untuk menerangkan nomina. Adapun analisis kesalahan penggunaan semete adalah sebagai berikut.

Adapun butir soal yang memuat fukushi semete adalah sebagai berikut.

1. Sono mise no se-ta- wa semete 10.000 en wa suru darou.

Itu/toko-GEN/sweater-

TOP/setidaknya/10.000/yen-

TOP/lakukan/mungkin

'Sweater di toko itu mungkin setidaknya seharga 10.000 yen'

2. Ima kara takushi ni nottemo, semete $10 \mathrm{ji}$ ni wa tsukenai.

Sekarang/dari/taksi-

DAT/naik/meskipun/setidaknya/jam 10-

TOP/tiba-btk.neg

'Meskipun dari sekarang naik taksi, setidaknya tidak tiba pukul 10'

3. Tokyo ni iku nara, semete ippaku wa shitai.Tokyo-

LOK/pergi/kalau/setidaknya/satu hariTOP/lakukan-btk.ingin'Kalau pergi ke Tokyo, setidaknya ingin menginap sehari'

4. Senshuu no tesuto wa jishin ga nakatta ga, semete 50 ten wa toreta.Minggu laluGEN/tes-TOP/percaya diri/tapi/adabtk.neg/tapi/setidaknya/nilai

50/dapat'ujian minggu lalu tidak percaya diri, tapi setidaknya mendapat nilai 50'

Berikut adalah tabel hasil penghitungan frekuensi jawaban yang diberikan oleh responden.

Tabel 6. Tabel Frekuensi Jawaban Semete

\begin{tabular}{llllll}
\hline \multirow{3}{*}{ Semete } & Opsi jawaban & $(1)$ & $(2)$ & $(3)$ & $(4)$ \\
\cline { 2 - 6 } & Jawaban & 4 & 6 & 11 & 8 \\
& Persentase & $14 \%$ & $21 \%$ & $38 \%$ & $27 \%$
\end{tabular}

Jawaban benar: (3) Persentase kesalahan: 62\%

Berdasarkan tabel tersebut, pilihan jawaban yang paling banyak dipilih oleh responden adalah pilihan jawaban nomor (3) sebanyak 11 orang. Pilihan jawaban nomor (1) dipilih sebanyak 4 orang. Pada pilihan jawaban nomor (2) sebanyak 6 orang dan pilihan jawaban nomor (4) dipilih sebanyak 8 orang. Frekuensi jawaban salah terbanyak terdapat pada jawaban nomor (4). Persentase kesalahan jawaban yang diberikan oleh responden pada soal tersebut adalah $62 \%$.

Seperti yang dijelaskan sebelumnya, semete digunakan untuk mengekspresikan tingkat minimal kepuasan dari pembicara. Pada umumnya, penggunaan fukushi tersebut dalam kalimat diikuti dengan ekspresi harapan dan keinginan seperti tai 'ingin'. Semete umumnya digunakan untuk menerangkan nomina. 
Pada soal ini, responden paling banyak menjawab salah terdapat pada pilihan jawaban (4) sebanyak 8 responden. Penggunaan semete pada kalimat (4) tidak tepat karena kalimat tersebut tidak mengungkapkan harapan dari subjek. Hal yang dibicarakan oleh subjek telah terjadi, sehingga penggunaan semete pada kalimat tersebut tidak tepat. Pada pilihan jawaban (1) penggunaan semete tidak tepat karena pada kalimat tersebut, semete digunakan untuk menyatakan harga dari barang yang ada di toko tersebut. Hal tersebut tidak sesuai dengan makna dan penggunaan dari semete. Kemudian, pada pilihan jawaban (2) penggunaan semete tidak tepat karena dalam kalimat tersebut menyatakan perkiraan. Pilihan jawaban (3) merupakan penggunaan semete yang tepat karena menyatakan keinginan dari subjek. Pada kalimat tersebut terdapat ekspresi keinginan tai 'ingin', sehingga penggunaan semete pada kalimat tersebut tepat.

\section{PENUTUP}

Berdasarkan Fukushi atau dalam istilah bahasa Indonesia yang disebut dengan adverbia adalah suatu jenis kata yang sifatnya memberikan keterangan terhadap verba dan adjektiva. Fukushi memiliki penggunaannya tersendiri sesuai dengan makna yang terdapat pada fukushi tersebut. Dalam kalimat, beberapa fukushi juga muncul disertai dengan ekspresi yang umumnya mengikuti fukushi tersebut.

Berdasarkan hasil tes yang diberikan kepada responden (mahasiswa), diketahui bahwa frekuensi kesalahan terendah terdapat pada butir soal yang memuat fukushi zuibun. Frekuensi kesalahan pada zuibun sebanyak 7 dengan persentase $24 \%$ dengan interpretasi kesalahan rendah. Pada butir soal yang memuat fukushi sukkari frekuensi kesalahan sebanyak 15 dengan interpretasi kesalahan tersebut adalah sedang. Kemudian, frekuensi kesalahan tertinggi terdapat pada butir soal yang memuat fukushi semete, yaitu frekuensi kesalahan sebanyak 18 dengan interpretasi kesalahan penggunaan fukushi semete adalah cukup tinggi.

\footnotetext{
Berdasarkan analisis kalimat dan hasil jawaban dari responden, responden cenderung menerjemahkan secara harafiah fukushi-fukushi tersebut. Responden kurang mengetahui makna dan penggunaan fukushi tersebut dengan tepat, sehingga terjadi kesalahan di dalam memilih kalimat yang tepat sesuai dengan fukushi tersebut. Pemahaman mengenai fukushi secara tepat menjadi faktor
}

yang penting dalam pembelajaran bahasa jepang. Ini dilakukan agar pembelajar dapat menggunakan fukushi dengan baik dan benar. Jika peserta didik mampu memahami fukushi dengan benar, maka kemampuan peserta didik dalam menggunakan fukushi pun akan semakin meningkat. Dari penelitian yang dilakukan, diharapkan dapat dijadikan bahan evaluasi serta untuk mencari solusi dalam mencari metode pembelajaran yang tepat untuk meningkatkan kemampuan penggunaan fukushi.

\section{DAFTAR PUSTAKA}

Koizumi, Tamostu. 1995. Nihongo Kyouiku no Tame ni Gengogaku Nyuumon. Tokyo: Daishukan Shoten Kabushiki Gaisha

Makino, Seiichi \& Tsutsui, Michio. 1996. A Dictionary of Intermediate Japanese Grammar. Japan: The Japan Times

Mulya, Komara. 2013. Fukushi Bahasa Jepang. Tanggerang: Graha IImu

Noviastuti, Endah. 2017. Klasifikasi Bentuk Shouryakugo1 Dalam Bahasa Jepang. $\begin{array}{llll}\text { Jurnal Parafrase } & \text { Vol. } 17 & \text { No.02 }\end{array}$ Oktober 2017 Universitas Negeri Surabaya

Nusarini. 2017. Adverbia Dalam Bahasa Indonesia: Tinjauan Bentuk Dan Perilaku Semantisnya . Jurnal Caraka, Volume 3, Nomor 2, Edisi Juni 2017 Pendidikan Bahasa dan Sastra Indonesia FKIP Universitas Sarjanawiyata Tamansiswa Yogyakarta

Sudjianto, dan Dahidi, Ahmad. 2018. Pengantar Linguistik Bahasa Jepang. Jakarta: Kesaint Blanc

Susanti, Elvi. 2016. Glosarium Kosakata Bahasa Indonesia Dalam Ragam Media Sosial . Jurnal bahasa, sastra, dan pendidikan bahasa dan sastra Indonesia, 3(2), 2016

Tsujimura, Natsuko. 2004. An Introduction to Japanese Linguistics. United Kingdom: Blackwell Publishing 
Wahidati, Lufi. 2018. Pengaruh Konsumsi Anime Dan Manga Terhadap Pembelajaran Budaya Dan Bahasa Jepang . Jurnal Sekolah Vokasi UGM Izumi, Volume 7 No 1, 2018

Yuliani, Siti. 2018. Efektivitas Word Mapping Untuk Meningkatkan Kemampuan Mengingat Kosakata Bahasa Jepang Siswa Kelas Xi Sma N 7 Semarang . Journal of Japanese Learning and Teaching CHI'E 6 (1) (2018) 